\title{
Dinâmica do uso e ocupação da terra a bacia hidrográfica do arroio Olarias, Ponta Grossa-Pr, entre 1995 e 2005
}

\section{Dynamics of land use and occupation at the Olarias stream hydrographic basin in Ponta Grossa, state of Paraná, Brazil, between 1995 and 2005}

\author{
Sérgio Ricardo Rogalski \\ Silvia Méri Carvalho \\ Universidade Estadual de Ponta Grossa
}

Resumo: O objetivo deste trabalho é analisar a dinâmica do uso e ocupação da terra da bacia hidrográfica do arroio Olarias, no município de Ponta Grossa-PR, entre 1995 e 2005. Para identificação das classes de uso da terra, utilizou-se o Manual Técnico de Uso da Terra do Instituto Brasileiro de Geografia e Estatística - IBGE (2006), cujas classes elencadas para este estudo foram: Urbano, Floresta, Agrícola, Campestre e Reflorestamento. A elaboração dos mapas de uso da terra utilizou como ferramentas os recursos oferecidos pelas geotecnologias para manipulação, atualização e espacialização das classes. Por ser uma bacia hidrográfica com ocupação predominantemente urbana, a classe Floresta apresentou uma redução de área de 8,24\%, no período analisado, sendo substituída pela expansão urbana e agricultura. A classe Agrícola apresentou uma pequena redução no período estudado, o que demonstra que essa atividade ainda é expressiva mesmo em uma bacia urbana. A classe Reflorestamento apresentou a maior área de uso identificada neste estudo e também sofreu redução de 1,42\% sendo substituída pela expansão do uso urbano, o que aponta a possível erradicação dessa atividade para os próximos anos.

Palavras-chave: Uso da terra. Bacia hidrográfica. Geotecnologias.

\begin{abstract}
The aim of the present paper is to analyze the dynamical land use and occupation at the hydrographic basin of the Olarias stream, in Ponta Grossa, state of Paraná, Brazil, between the years 1995 and 2005. In order to identify the classes of land use, the Technical Manual for Land Use (2006) of the Brazilian Institute for Geography and Statistics - IBGE was used. The following classes were listed in this Manual: Urban, Forest, Agricultural, Rural and Reforestation. The elaboration of the maps for land use employed as tools the resources provided by the geotechnology for the manipulation, updating and spatial distribution of the classes. Since the hydrographic basin presents a predominantly urban occupation, the Forest class showed an area reduction of $8.24 \%$ in the studied period, being replaced by the urban growth and rural activities. The Agricultural class presented a small decreasing during the same period, which demonstrates that this activity is still expressive, even in an urban basin. In this study, the Reforestation class showed the greatest occupation area, although it has also suffered a $1.42 \%$ reduction, being replaced by urban expansion. This indicates a potential eradication of the latter activity for the next years.
\end{abstract}

Keywords: Land use. Hydrographic Basin. Geotechnologies. 


\section{INTRODUÇÃO}

Na região do arroio Olarias a ocupação foi influenciada pelo ambiente físico e pelas oportunidades de empregos criadas pela Rede Ferroviária Federal Sociedade Anônima - RFFSA, indústrias madeireiras e olarias de cerâmicas existentes na área da bacia hidrográfica. (SILVA, 1997). Essa ocupação iniciou-se a partir dos divisores de água, pois eram as áreas de relevo mais plano. Contudo, atualmente também os fundos de vale são alvo da expansão urbana.

O crescimento urbano ao longo dos anos no município de Ponta Grossa não foi acompanhado por um planejamento que levasse em consideração as particularidades do meio físico. (MEDEIROS; MELO, 2001). O município de Ponta Grossa apresenta um relevo bastante acidentado, o que é considerado como impedimento para a integração urbana. (BERTO, 2008).

A bacia hidrográfica do arroio Olarias está localizada na porção centro-sudeste do município, entre as coordenadas UTM/ SAD69-693172/7215231 e589079/7225541, Fuso $22 \mathrm{~J}$ (Figura 1). Possui uma área de 2.711,77 ha com uma população de 70.099 habitantes segundo censo demográfico do IBGE (2000).

O arroio Olarias é afluente da margem direita do rio Cará-Cará, apresenta uma rede de drenagem dendrítica e é classificado como de $4^{\text {a }}$ ordem (escala 1: 50.000), conforme a hierarquização de rios proposta por Strahler (1957). Em seu curso é comum a presença de cachoeiras e corredeiras, mais precisamente na porção superior da bacia hidrográfica do arroio Olarias. (MELO; GODOY, 1997).

A bacia em questão situa-se sobre a Formação Ponta Grossa unidade de topo do Grupo Paraná, do Período Devoniano da Bacia do Paraná, apresentando raras e delgadas intercalações de arenitos finos com rochas intrusivas mesozoicas (Magmatismo Serra Geral) sob a forma de soleiras e diques de diabásio. Nas planícies de inundação e talvegues encontram-se depósitos recentes representados por aluviões, leque aluvial, rampas colúvioaluviais e terraços aluviais. (MELO e GODOY,1997).

De acordo com a Empresa Brasileira de Pesquisa Agropecuária - EMBRAPA (2008), as classes de solos que predominam na bacia de Olarias são: Latossolos Vermelho Distróficos, Cambissolos Háplicos Alumínicos, Gleissolos Melânicos e Neossolos Litólicos Húmico. Em sua maioria são argilosos, desenvolvidos a partir do folhelho da Formação Ponta Grossa, sendo que apenas uma pequena porção encontra-se sobre os diques e soleiras de diabásio.

Nos locais onde o diabásio aflora na bacia, as declividades dos terrenos tendem a ser maiores, pois essa é uma rocha mais resistente do que os folhelhos da Formação Ponta Grossa. Quando os rios se instalam sobre as rochas de diabásio, o leito tende a ser rochoso e/ ou há formação de corredeiras e cachoeiras.

O relevo da bacia é caracterizado por três diferentes compartimentos: interflúvios extensos e aplainados, encostas e fundo de vales. A superfície dos interflúvios apresenta colinas e morretes. Muitas cabeceiras dos rios da bacia estão instaladas sobre esse compartimento. As encostas possuem segmentos com diferentes inclinações e patamares em função das diferenças de resistências das rochas que a compõem. Os fundos de vale apresentam diferentes formas, abertos ou fechados, de acordo com a ordem dos rios e com a resistência das litologias onde são escavados. Por exemplo, rios que se desenvolvem sobre litologias mais 
resistentes tendem a apresentar canais mais largos porque não é possível o aprofundamento.

Os desníveis na bacia são pouco significativos, os interflúvios mais altos atingem 967,8 m (Praça Marechal Floriano Peixoto, Centro), enquanto na desembocadura do rio Cará-Cará, a cota é de 783,5 m, contudo as declividades podem ser acentuadas.

Para Carvalho (2004), ao analisar uma bacia hidrográfica, o pesquisador deverá reconhecer os seus elementos fundamentais, assim como as ligações com o seu contexto. Sendo os aspectos principais o uso da terra e sua caracterização do meio físico e ecossistemas (geologia, solos, relevo, clima, hidrologia, cobertura vegetal). A análise do uso e ocupação da terra é importante na compreensão de estudos de bacias hidrográficas porque tratam das atividades humanas, suas pressões e também as transformações ambientais. (SANTOS, 2004).

O objetivo deste trabalho é analisar a dinâmica do uso e ocupação da terra da bacia hidrográfica do arroio Olarias, município de Ponta Grossa-PR, entre 1995 e 2005, utilizando os procedimentos presentes no Manual Técnico de Uso da Terra do Instituto Brasileiro de Geografia e Estatística - IBGE (2006).

A bacia hidrográfica do arroio Olarias está localizada no perímetro urbano de Ponta Grossa, contudo ainda persistem atividades agrícolas na área, o que aponta relevância para o presente estudo. As informações aqui obtidas podem demonstrar também os cenários futuros em relação ao uso inadequado da terra.

A disponibilidade de informações atualizadas e de fácil tratamento é primordial para estudos ambientais, por isso, dentro dos recursos da área das geotecnologias, o geoprocessamento, o sensoriamento remoto e os sistemas de informação geográfica (SIG) têm sido amplamente utilizados.

Sendo assim, este estudo utilizou-se desses recursos, cujo processamento e manuseio dos dados e técnicas foram feitos no software ArcView GIS ${ }^{\circledR}$ versão 3.2. Nesse sentido, o Sistema de Informação Geográfica - SIG tem sido uma ferramenta metodológica fundamental para análise e cruzamento de informações de forma fácil e ágil para estudos ambientais. 
Figura 1 - Localização da bacia hidrográfica do arroio Olarias

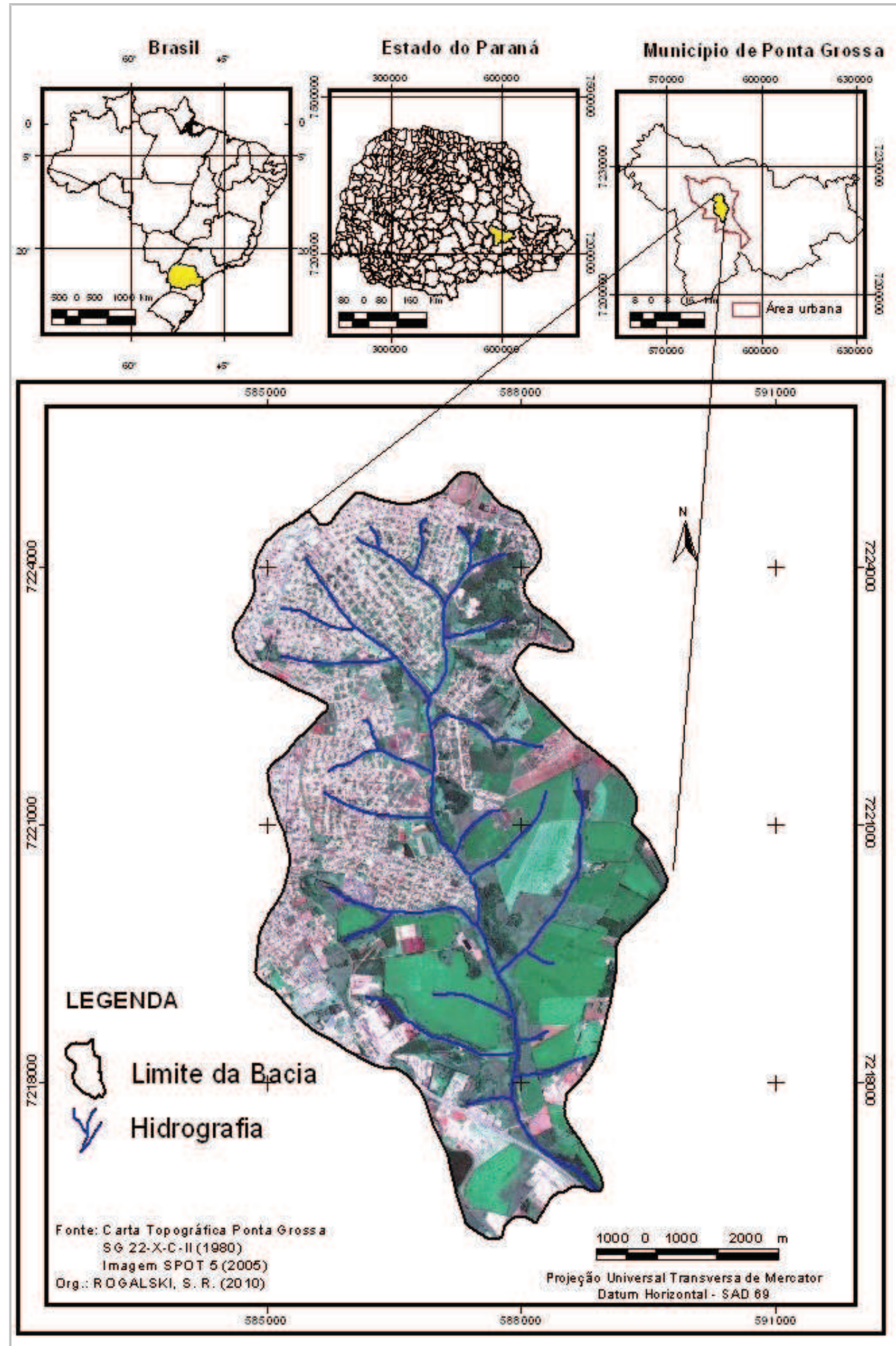




\section{A RELAÇÃO ENTRE SOCIEDADE E NATUREZA EM ESTUDOS DE BACIAS HIDROGRÁFICAS}

A ciência geográfica, enquanto ciência social, busca compreender a sociedade em sua dimensão espacial. Nesse sentido, os estudos que envolvem a dinâmica da sociedade e da natureza na constituição do espaço têm contribuído no âmbito da discussão dessa ciência com relação às questões ambientais. Essas questões encontram-se voltadas para estudos que visam à análise socioambiental do espaço geográfico, onde o homem é centro dos efeitos dessa relação.

Os problemas ambientais têm sido evidenciados a partir das derivações da relação sociedade-natureza, nas suas mais diversas escalas de análise, cujo objetivo atual é elencar estratégias que viabilizem o melhor aproveitamento dos recursos naturais e com menor impacto possível, portanto, compatibilizando atividades econômicas com qualidade ambiental. (CARVALHO, 2009). A autora ressalta ainda que,

Uma das questões primordiais em pesquisas ambientais é a definição de unidades ambientais homogêneas para viabilizar o espaço de pesquisa, abarcando as novas demandas no enfrentamento de grandes desafios ambientais, seja em escala local ou global e de maneira integrada. (CARVALHO, 2009, p. 201).

A noção de que os recursos naturais seriam inesgotáveis desencadeou os sinais da chamada crise ambiental na década de 1960 e 1970, a questão ambiental então emerge em muitos campos do conhecimento para tratar de um novo rumo no que tange ao uso dos recursos naturais e a relação sociedade-natureza. Nesse sentido, a perspectiva mais contundente diante dessa crise foi a de assumir o homem enquanto parte integrante nas questões ambientais.
A ação antrópica foi incorporada nos estudos ambientais em bacias hidrográficas, como elemento do sistema que condiciona fluxos de matéria e energia, o qual altera o comportamento ou equilíbrio natural dos geossistemas. Segundo Lima (2005), os geossistemas seriam uma abordagem da Geografia Física cujo enfoque em seus estudos é a dinâmica dos aspectos naturais buscando incorporar os aspectos antrópicos.

No Brasil, a partir da década de 1970 e início dos anos 1980, emergiu a tendência de elaborar planejamentos regionais integrados com elementos provenientes do meio natural ou antropizado. Assim, a bacia hidrográfica passa a ser considerada nessa perspectiva como a melhor unidade ambiental de análise e gestão. (SANTOS, 2004).

A bacia hidrográfica, nesse contexto, justifica-se por representar um sistema natural bem delimitado no espaço, abranger uma unidade geográfica onde os recursos naturais se integram e, sobretudo, por constituir-se numa unidade espacial de fácil reconhecimento e caracterização, que contém as interações e pressões sobre os sistemas naturais ou criados pelo homem. (SANTOS, 2004).

A partir disso, a bacia hidrográfica apresenta-se como uma unidade de análise, para aplicação de diversos estudos, sendo um deles o uso e ocupação da terra, pois, segundo Santos (2004), esse é um dos temas básicos para planejamento ambiental, por tratar das atividades humanas e suas pressões, bem como das transformações ambientais.

Por meio da caracterização, diagnósticos e dados da ação humana na bacia hidrográfica são desenvolvidas diversas análises, apontando, assim, as necessidades de intervenções e de infraestrutura urbana e ambiental para elaboração de um planejamento ambiental. Além disso, o estudo de uso e ocupação da 
terra pode apontar os conflitos ambientais existentes na bacia hidrográfica que estão em desacordo com a legislação ambiental e urbana vigente.

Numa bacia hidrográfica, os elementos do quadro natural e social interagem e evoluem no espaço e no tempo. (CARVALHO, 2004). Nesse sentido, a relação sociedade-natureza nos estudos ambientais remete a uma visão integrada do ambiente físico e dos processos antrópicos que se desenvolvem na área. $\mathrm{O}$ uso da terra reflete, portanto, a interação dessa dinâmica espacial.

Sendo assim, o uso da terra pode ser compreendido como o espaço apropriado pelo homem para estabelecimento de infraestruturas básicas para sua sobrevivência, como habitação, tráfego, comunicação, geração de energia, industrialização, produção de alimentos além de bens obtidos da agropecuária e silvicultura. (BRIASSOULIS, 2000).

O uso e ocupação da terra é um elemento importante para análise ambiental, pois permite a identificação e localização dos agentes responsáveis pelas condições ambientais de uma determinada área. (SANTOS, 2004). A aplicação desse conhecimento é essencial para auxiliar no planejamento ambiental e gestão do território. Segundo o Manual Técnico de Uso da Terra do IBGE (2006, p. 06),

O conhecimento sobre o uso da terra ganha relevo pela necessidade de garantir a sua sustentabilidade diante das questões ambientais, sociais e econômicas a ele relacionadas e trazidas à tona no debate sobre o desenvolvimento sustentável.

O uso e ocupação da terra é um estudo que permite descrever a situação atual (análise), como também o histórico da ocupação da área de estudo (dinâmica) e, segundo Santos (2004, p. 97), "retrata as atividades humanas que podem significar pressões sobre os elementos naturais".
É importante destacar que o levantamento de elementos ou classes que identificam o uso e ocupação da terra de um determinado ambiente está relacionado com a distribuição geográfica de seus diferentes usos, devendo suas aplicações e adequações atender às particularidades dos ambientes.

Os estudos utilizando bacias hidrográficas como unidades de análise integrada permitem compreender os elementos que interagem indissociavelmente na relação sociedadenatureza, ou seja, o econômico, político, social e cultural, segundo a abordagem socioambiental proposta por Mendonça. (2001).

Cunha e Guerra (2000, p. 337) entendem a bacia hidrográfica enquanto "uma unidade integradora de setores sociais e naturais e deve ser administrada com esta função a fim de minimizar os impactos ambientais". Nessa perspectiva, Carvalho (2004, p. 36) entende também que "a bacia hidrográfica como unidade de estudos pode ser considerada como a expressão, em diversas escalas, da interação da sociedade e natureza na produção do espaço". Os estudos de bacias hidrográficas ganharam novos lineamentos na medida em que o homem foi inserido de forma indissociável como agente atuante dessa unidade ambiental.

No estudo da relação sociedade-natureza em bacias hidrográficas, deve-se considerar a caracterização do uso e ocupação da terra como um dos principais trabalhos a ser realizado, pois permite identificar os conflitos ambientais existentes na bacia e ainda os usos e ocupações que estão em desacordo com a legislação ambiental e urbana vigente. A integração dessas informações e o cruzamento de mapas temáticos em ambiente SIG permitem o desenvolvimento da pesquisa, o que torna possível avançar nos diagnósticos. 


\section{METODOLOGIA}

A base cartográfica e as fontes para elaboração dos mapas temáticos de uso da terra foram disponibilizadas por duas fontes:

1) Laboratório de Geoprocessamento da Universidade Estadual de Ponta Grossa UEPG - Mapa Topográfico Folha de Ponta Grossa escala 1:50.000 - SG 22-X-C-II/2 DSG, ano 1980; Ortoimagem do sensor SPOT 5, resolução espacial $5 \mathrm{~m}$ cedida pela Secretaria do Estado do Paraná de Desenvolvimento Urbano - Sedu/ Paranacidade. A partir disso foi possível a elaboração do mapa de uso e ocupação da terra da bacia hidrográfica do arroio Olarias para o ano de 2005.

2) Base cartográfica: voo aerofotogramétrico de 1995, escala 1:8.000 obtida junto ao setor de Cadastro Técnico Municipal - Secretaria de Planejamento da Prefeitura Municipal de Ponta Grossa / Fundo de Assistência aos Municípios do Estado do Paraná - FAMEPAR; presente no trabalho de Diedrichs (2001). A partir do mapa de vegetação foi possível gerar o mapa de uso e ocupação da terra para o ano de 1995, após uma redefinição das classes de uso.

Para elaboração dos mapas de uso e ocupação da terra da bacia hidrográfica do arroio Olarias de 1995 e 2005 foram utilizados os recursos das geotecnologias de ambientes SIG e sensoriamento remoto, com os softwares Arc View GIS ${ }^{\circledR} 3.2$ e Envi 3.6 (Enviroment for Visualing Images).

Para realização deste estudo utilizouse também o Manual Técnico do Uso e Ocupação da Terra do IBGE (2006), no qual foram adaptadas as seguintes classes:

Urbano: compreende áreas de uso intensivo, estruturadas por edificações e sistema viário, onde predominam as superfícies artificiais não agrícolas;
Floresta: classe correspondente às formações arbóreas, na forma de fragmentos ou de forma contínua;

Campestre: classe das formações vegetais não arbóreas, aquelas que se caracterizam por um estrato predominantemente arbustivo, esparsamente distribuído por um tapete gramíneo - lenhoso;

Agrícola: enquadram-se aí todas as terras cultivadas. Encontram-se inseridas nesta categoria as lavouras temporárias, lavouras permanentes, pastagens plantadas e silvicultura;

Reflorestamento: Classe que corresponde às áreas com plantio ou formação de maciços com espécies florestais nativas ou exóticas. Para esta bacia hidrográfica foi identificado o reflorestamento de eucalipto (Eucalyptus spp).

\section{RESULTADO E DISCUSSÕES}

Foram elaborados dois cenários temporais para o uso e ocupação da terra da bacia hidrográfica do arroio Olarias para os anos de 1995 (Figura 2) e 2005 (Figura 3), nos quais foram identificadas cinco classes de uso, como demonstrado no Gráfico 1. 
Gráfico 1 - Uso da terra da bacia hidrográfica do arroio Olarias.

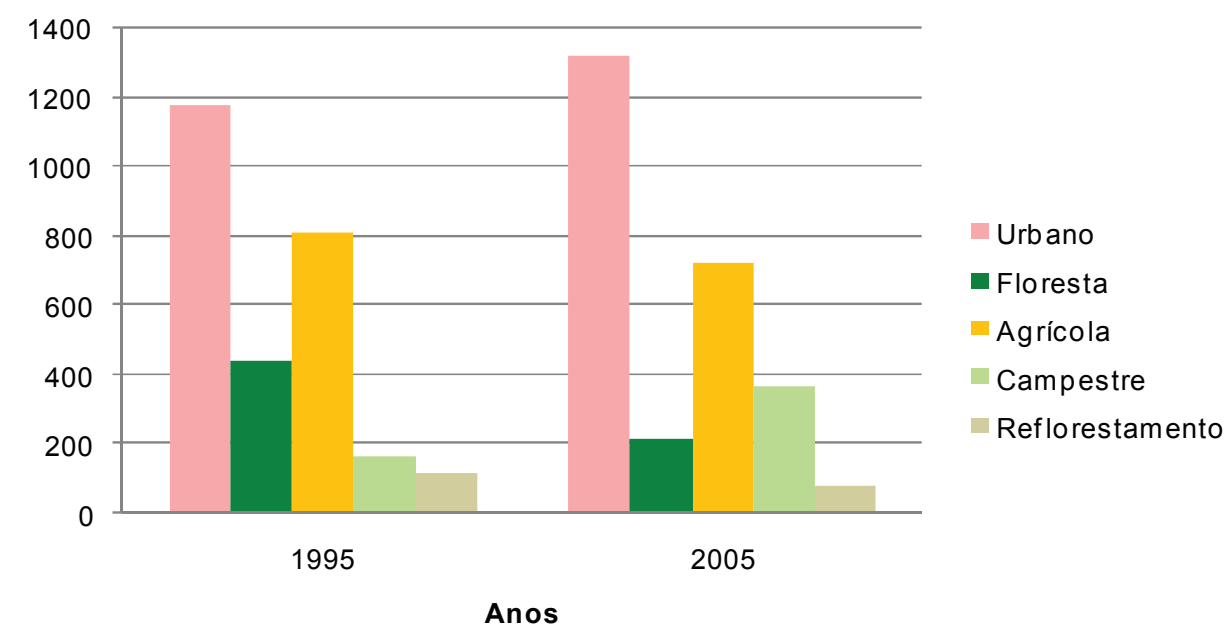

Fonte: ROGALSKI (2010).

Figura 2 - Uso e ocupação da terra da bacia hidrográfica do arroio Olarias - 1995

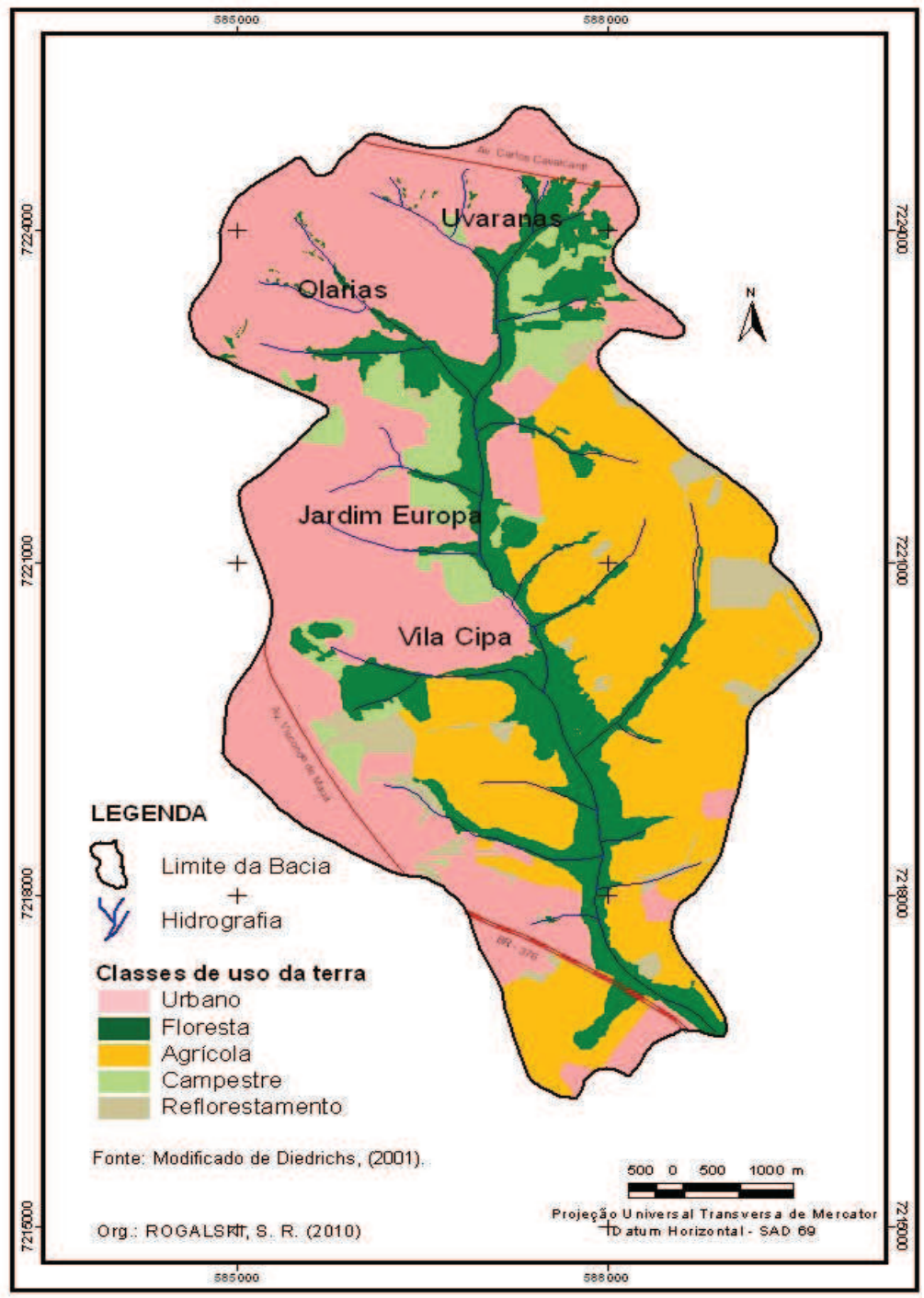


Figura 3 - Uso e ocupação da terra da bacia hidrográfica do arroio Olarias - 2005

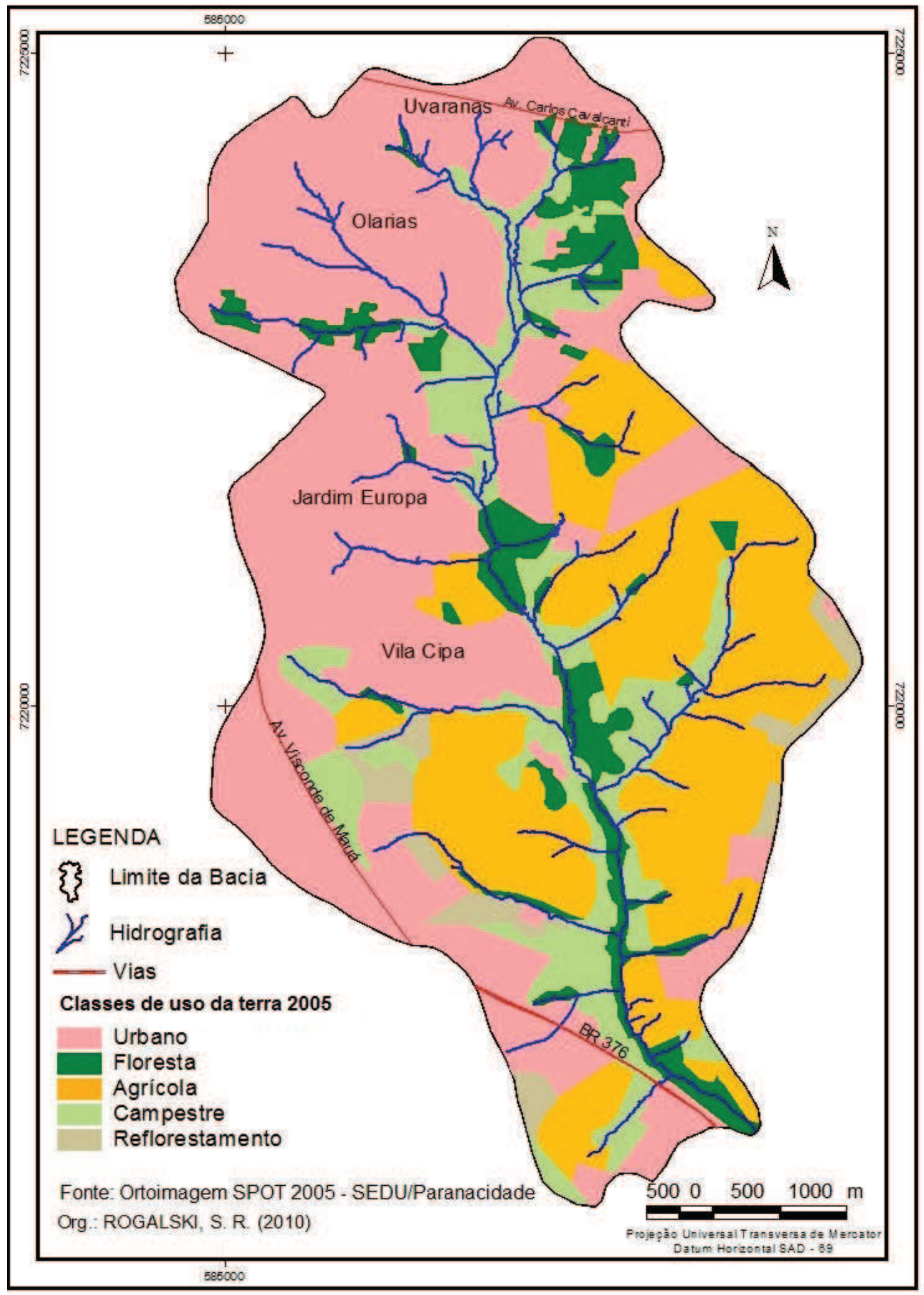

A classe de uso Urbano foi a que mais aumentou no período estudado $(16,11 \%)$, estando localizada mais significativamente nas porções leste e sul da bacia e ainda na porção centro/leste, compreendendo $43,37 \%$ da área total. O crescimento da população urbana, conforme SAHR (2001), não leva apenas ao aumento da densidade demográfica, mas também à expansão da malha urbana. Essa expansão ocorreu por causa da implantação de loteamentos, como: Jardim Alto Alegre, São Gabriel, 
Estrela do Lago, Vitória Régia, Jardim Esperança realizado pela Companhia de Habitação de Ponta Grossa - PROLAR, e pelos loteamentos fechados Parque dos Franceses e Vêneto pelo mercado imobiliário. Esses loteamentos estão em áreas destinadas à expansão urbana previstas pelo Plano Diretor do município.

A cobertura vegetal da bacia foi dividida em duas classes: Floresta e Campestre. A classe Floresta corresponde ao remanescente da Floresta Ombrófila Mista e apresentou uma redução de 18,24\% no período estudado. Sua presença era observada principalmente na cabeceira da bacia e na forma de mata de galeria ao longo dos cursos d'água, inclusive do arroio Olarias.

$\mathrm{O}$ valor correspondente à redução da classe Floresta deve-se ao aumento de $7,58 \%$ da classe Campestre para uso como pastagem, bem como o aumento da classe de uso Urbano destinada para expansão urbana e da classe Agrícola para instalação de novas lavouras.

As classes Campestre e Floresta estão distribuídas predominantemente ao longo dos cursos de água, cujas áreas são destinadas para preservação permanente, segundo o Código Florestal Brasileiro.

Sobre a classe Floresta, Diedrichs (2001) identificou áreas potenciais para criação de Unidades de Conservação (UCs) que poderiam ser propostas ao poder público, podendo assim constituir um corredor ecológico ao longo do curso do arroio Olarias. A presença de Floresta Ombrófila Mista em uma bacia hidrográfica urbana despertou o interesse da implementação de uma Reserva Particular de Patrimônio Natural (RPPN) na cabeceira da bacia, a qual seria gerida pelo Centro de Ensino Superior dos Campos Gerais (CESCAGE), o que permitiria então a criação de um grande parque linear.

Entretanto não foram criados nem a RPPN e nem o parque linear nesse período e, atualmente, a gestão pública municipal demonstra interesse na criação de um lago recreativo na porção média da bacia do arroio Olarias. Contudo, os primeiros esforços foram negativos, pela falta de informações sobre a bacia hidrográfica e em relação à poluição hídrica.

A classe Agrícola apresentou uma redução de 3,21\% principalmente nas áreas localizadas no terço-médio do vale, junto à margem esquerda do rio. Essa redução foi promovida em especial pela expansão urbana, mas também foi observado o abandono da atividade agrícola e a regeneração da vegetação nativa na forma de vegetação pioneira.

A bacia hidrográfica do arroio Olarias está compreendida dentro do perímetro urbano e, nessas áreas agrícolas, segundo os planos diretores do município, estão previstas a expansão urbana, porém a atividade agrícola na bacia ainda é expressiva.

A classe Reflorestamento é considerada como silvicultura, porém é importante destacar que essa atividade é significativa no município e na região dos Campos Gerais, o que permite elencá-la como classe individualizada neste estudo. Entretanto, foi a classe com menor área de ocorrência do período estudado, o que demonstra que essa atividade vem diminuindo ao longo dos anos.

A classe Reflorestamento teve uma redução de 1,52\%, substituída em parte pela classe Urbano, principalmente nas porções oeste e sul da bacia onde encontram-se algumas das indústrias do município de Ponta Grossa. Outra parcela de reflorestamento foi substituída pela classe Agrícola na porção leste da bacia, onde estão concentradas as atividades agrícolas. Essa dinâmica se deve à ocupação da bacia ao longo dos anos, cujas áreas deveriam estar previstas para expansão urbana conforme a legislação 
municipal vigente sobre o zoneamento urbano, Lei n. $.^{\circ} 4.856 / 92$.

\section{CONSIDERAÇÕES FINAIS}

A identificação das classes do uso e ocupação da terra da bacia hidrográfica do arroio Olarias neste estudo permitiu fazer observações acerca das transformações ocorridas no período de 1995 a 2005. A classe Floresta foi a que mais apresentou alterações, ou seja, redução com consequente substituição pelas classes Urbano, Agrícola e Campestre.

Em relação à cobertura vegetal, é importante salientar que a bacia hidrográfica do arroio Olarias apresenta uma significativa área de Floresta Ombrófila Mista com presença de Araucárias e campos nativos típicos da região ao longo dos cursos de água, o que evidencia a necessidade de um adequado ordenamento da mesma visando a preservação dessas formações fitogeográficas. Com isso, propostas de criação de parques lineares (Unidades de Conservação) para preservação dessas vegetações são relevantes pela gestão pública municipal.

Embora a bacia do arroio Olarias esteja inserida no perímetro urbano, as informações deste estudo demonstram que as atividades agrícolas ainda são intensas na área, sem grandes modificações em termos de área de abrangência nos dois períodos estudados, 29,94\% em 1995 e 26,73\% em 2005. Nesse sentido, os gestores públicos devem verificar, por meio do Plano Diretor Municipal, se os usos agrícolas atendem às aptidões, potencialidades e restrições de cada classe de uso da terra presente na bacia.

A classe Agrícola neste estudo são áreas potenciais à expansão urbana, como prevê a legislação municipal. A ausência de política de desenvolvimento urbano no município de Ponta Grossa é um fator antigo, de modo que talvez essa ausência possa explicar a presença ainda de atividades agrícolas no perímetro urbano.

A omissão ou inépcia dos princípios e diretrizes estabelecidas pela legislação ambiental e urbana do município possibilita que ocorram conflitos ambientais em decorrência do uso inadequado da terra ocasionando, assim, a sua degradação ambiental. Este estudo demonstrou que a classe Floresta tem sido reduzida por causa do não cumprimento da legislação ambiental vigente, o que aponta a existência de conflitos ambientais na referida bacia.

A classe Reflorestamento também diminuiu e apresenta em 2005 apenas $2,98 \%$ do total da área da bacia, o que demonstra que essa atividade pode ser erradicada nos próximos anos e que em áreas urbanas vem sendo substituída principalmente pela urbanização.

Cabe destacar que o presente estudo foi elaborado a partir de dados disponíveis, mas podem ser acrescidos outros parâmetros e temáticas, na compreensão da dinâmica do uso da terra, como a legislação ambiental vigente e os planos diretores. A importância da elaboração de mapas cujas temáticas são relevantes para o planejamento ambiental, assim como o auxílio oferecido atualmente pelas geotecnologias, mostram-se também de grande valor para esse planejamento. O objetivo deste trabalho foi analisar a dinâmica do uso e ocupação da terra da bacia hidrográfica do arroio Olarias, enquanto tema básico. A partir dos resultados aqui discutidos é possível analisar outras questões, tais como os conflitos ambientais, avançando assim nos diagnósticos ambientais. 


\section{REFERÊNCIAS}

BERTO, V. Z. A análise de qualidade ambiental urbana na cidade de Ponta Grossa (PR): avaliação de algumas propostas metodológicas. Ponta Grossa, 2008. Dissertação de Mestrado em Geografia - Área de Gestão do Território. Universidade Estadual de Ponta Grossa.

BRIASSOULIS, H. Analysis of land use change: theoretical and modeling approaches. Lesvos, Greece. Tese (Doutorado em Geografia) - University of Aegean, 2000. Disponível em: <http:/ / www.rri. wvu.edu/WebBook/Briassoulis/contents.htm>. Acesso em: 28 out. 2010.

CARVALHO, M. S. O Diagnóstico FísicoConservacionista - DFC como subsídio à Gestão Ambiental da Bacia Hidrográfica do Rio QuebraPerna, Ponta Grossa - PR. Presidente Prudente, 2004. Tese de Doutorado. Pós-Graduação em Geografia, área de concentração: Produção do Espaço Geográfico. Universidade Estadual Paulista.

M. S. A contribuição dos estudos em bacias hidrográficas para abordagem ambiental na geografia. In: Mendonça, F de A.; LÖWENSAHR, C. L.; SILVA, M. da (Org.). Espaço e tempo: complexidade e desafios do pensar e do fazer geográfico. Curitiba: ADEMADAN, 2009.

CUNHA, L. A.; GUERRA, A. J. T. Degradação ambiental. In: Geomorfologia e meio ambiente. Rio de Janeiro: Bertrand Brasil, 2000, p. 337.

DIEDRICHS, L. A. Os problemas ambientais e a urbanização da bacia hidrográfica do arroio Olarias - Ponta Grossa/PR. Curitiba: 2001. Dissertação de Mestrado. Pós-Graduação em Geografia, área de concentração: Produção do Espaço Urbano e Regional, Setor de Ciências da Terra. Universidade Federal do Paraná.

EMBRAPA. Empresa Brasileira de Pesquisa Agropecuária. Carta de Solos, folha SG-22-X-C MIR - 513 - 1:25.000, 2008.

IBGE. Instituto Brasileiro de Geografia e Estatística, Banco de dados. Disponível em: <http://www. ibgegov.br/home/estatistica/populacao/defaut_ censo_2000.shtm/ >. Acesso em: 24 maio 2010.

Manual Técnico de Uso da Terra. Séries Manuais Técnicos em Geociências. 2. ed. Rio de Janeiro, n. 7, 2006.

LIMA, A. G. A bacia hidrográfica como recorte de estudos em geografia humana. GEOGRAFIA - v.
14, n. 2, jul./ dez. 2005 - Universidade Estadual de Londrina, Departamento de Geociências.

MEDEIROS, C. V.; MELO, M. S. de. Processos erosivos no espaço urbano de Ponta Grossa. In: DITZEL, Carmencita de Holleben Mello e SAHR, Cecilian Luiza Lowen (Org.). Espaço e cultura: Ponta Grossa os Campos Gerais. Ponta Grossa: EDUEPG, 2001.

MELO, M. S. ; GODOY, L. C. Geologia, geormofologia e riscos geológicos na bacia do arroio Olarias, Ponta Grossa, PR. Publicátio UEPG, Ciências Exatas e da Terra, Ponta Grossa, v. 3, n. 1, p. 33-59, 1997.

MENDONÇA, F. de A. Geografia e meio ambiente. São Paulo: Contexto, 2001.

PONTA GROSSA, Lei n. 4.856, de 28 de Dezembro de 1992. Dispõe sobre o zoneamento de uso e ocupação do solo em áreas urbanas do município de Ponta Grossa e dá providências (1992).

SANTOS, R. F. dos. Planejamento ambiental: teoria e prática. São Paulo: Oficina de Textos, p. $85,2004$.

SAHR, C.L.L. Estrutura interna e dinâmica social na cidade de Ponta Grossa. In: DITZEL, C. de H. M. e SAHR, C. L. L. (Org.). Espaço e cultura: Ponta Grossa os Campos Gerais. Ponta Grossa: Ed. UEPG, 2001.

SILVA, J. M. Relatório do Diagnóstico Sócio econômico da bacia do Arroio Olarias. NUCLEAN/ UEPG. (Inédito, 1997).

STRAHLER, A. N. Quantitative analysis of watershed geomorphology. Trans. Am. Geophys. Un., v. 38, p. 913-920, 1957.

Recebido em: 25/11/10 Aceito em: 23/01/11 